
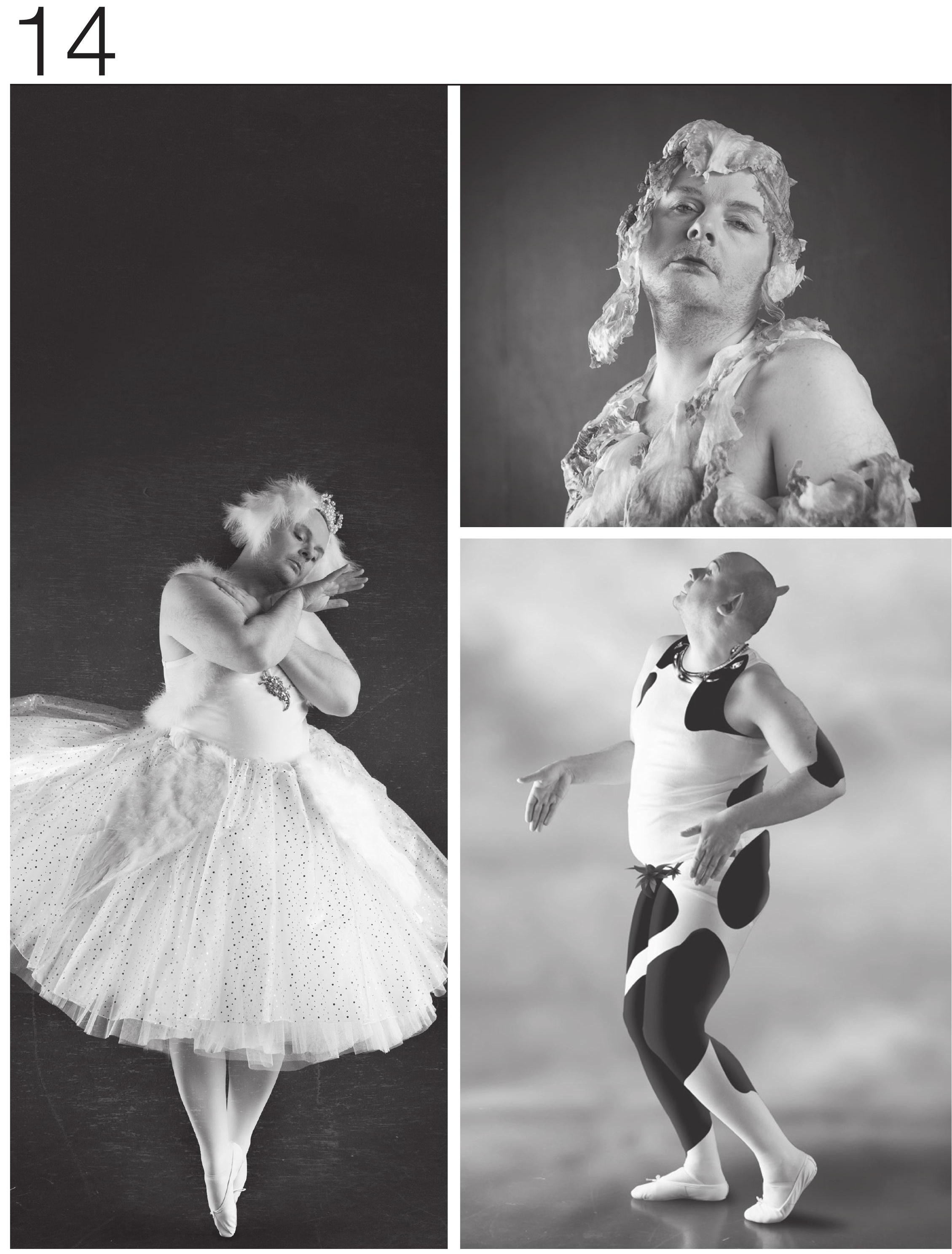

Clockwise from above left: Mark Edward as 'Angina' Pavlova in the dying swan pose, as Nijinsky in Le Spectre de la Rose and as Nijinksy in L' après-midi d'un faune. Photos: Dr Helen Newall 


\title{
Dying swans and dragged up dames
}

\author{
Mark Edward and Dr Helen Newall's photographic exploration screams for the beauty of the \\ ageing dancer
}

\begin{abstract}
We are standing in a darkened studio fluffing up tulle, changing camera batteries and fettling our cygnets' wings. One of us is dealing with the technicalities of the 580Ex Canon Speedlite; the other with the pain of 1960s vintage pink satin pointe shoes and cracked toenails. Welcome to our world of clothes pegs, safety pins, pancake tutus and faked fouettés.
\end{abstract}

Our latest joint project, Dying Swans and Dragged Up Dames, consists of a series of images, each of which parodies an iconic performance photograph of a legendary dancer. So far we've tackled Pavlova and Nijinsky. There is, however, serious intent to our play. That is the investigative methodology of practice as research, in which the doing reveals and interrogates the theory.

This project has two threads corresponding to our individual practice as research investigations: Mark's work, as a performance artist, investigates the implications of ageing for dance performers. Helen's work concerns performance photography, and the dissonances between performance photo-documentation and the performance itself.

Mark says, "we are positioned in a performance world of youth and media-driven agendas," and adds, "it seems that there comes an age when we're considered too old to be performers." Over the past few years, Mark has questioned the cultural expectation of 'dancing your age', and what this might be, through examination of popular representations of the dancing body. One of his dance works in 2008, Falling Apart at the Seams, memorably featured June Gibbons, an octogenarian veteran of the British Music Halls in the 1940s and 1950s (see Animated Winter 2011). Ms Gibbons reprised her tap and singing act, with a feisty rendition of On the Sunny Side of the Street. Whilst she was undoubtedly not as agile as before, and her voice no longer as strong, her performance had an embodied integrity formed out of experience and the aura of her heritage. Combined, this produced a living archive of former performances. Mark contends, "there is currency in the (hi)stories and creases that come with age. The body normative that the contemporary media portrays via repetitive imagery of the young and the able erases this living archive. We are the poorer for it."

In Dying Swans and another on-going project, The Yellow Wallpaper, Helen exposes via the camera how imagery resituates a performance which did not exist. Helen compares this to watching dancing by lightning. The photograph, she notes, idealises the heroic dance legend, even as the performance itself is past its dance-by-date. In dance marketing photographs, technique is always perfect. Impossible leaps are held forever. There is no sweat, no pain, and no thudding landings. And, of course, age is often erased if not by selection, then by lighting, and Photoshop. Photoshop can shift the lift of an arm or shave inches from a thigh. But Photoshop can only do so much. Generally, to be a dancer, and to be photographed, thou shalt be thin and thirteen.

As we have noted elsewhere, dance technique is traditionally about youth: dance is an athletic phenomenon celebrating an aesthetic of difficult, and often elitist, corporeal ability which only the young can achieve. Ageing, meanwhile, often signifies loss of ability and therefore, irrelevancy and sadly invisibility - see our Warsaw 2011 article. (1)

Dancers fade from view once they hit their mid to late thirties when younger, more agile bodies draw the gaze. Is this because as audiences we prefer not to be reminded of our own ageing? Perhaps the almost impossible achievements of young dancers, and for that matter sports and athletics stars, celebrate the pinnacle of human physical ability in a visceral way: while they defy gravity, and move harder, stronger, faster, we can forget our own physical mortality for an albeit brief moment. But if dancers don't fade from view, their age is often represented as comic and/ or threatening. Dr Sara Houston notes the traditional shift in ballet of mature dancers to character roles, but these roles are emphatic in their rejection of age: "The association of the older person with unattractiveness, with crankiness and above all with witches is played out in dance. These myths 
Dancers fade from view once they hit their mid to late thirties when younger, more agile bodies draw the gaze. Is this because as audiences we prefer not to be reminded of our own ageing? and representations of the older person are still endemic in Western culture and are still active in dance". (2)

We're not suggesting that older dancers be cast in roles that they can no longer physically accomplish. The physical and emotional demands of dance are, after all, exhausting. Technique, imposed on the body in a strict system of codification such as ballet, demands perfection. For whilst the young dancer is not immune to injury which might cut short a career, the older dancer is subject to the inevitable decline of what was once possible. To put it bluntly, ageing blunts technique. But this is where the body could write the dance instead of the dance being imposed on a body which can no longer accommodate inflexible technique. New choreographic practices could celebrate grace, memory, physical archives. If Pina Bausch can do it in 'Kontakthof', why can't others?

Dancers are often presented in movies and novels as fragile and ephemeral beings, rather than the tough athletes they are, used to the hard physical slog of daily class which gets harder with age. The archetype of the physically and/ or mentally injured dancer - Black Swan, The Red Shoes, and Benjamin Button - is a persistent and potent tragedy of performance beauty cut short. You can see the scriptwriters' point of view: the sudden twisted ankle (simultaneously rendering the heroine helpless, whilst reinforcing her frail beauty) is more dramatic than the rheumatic knee, which creaks with each développé at the barre.

And what of drag queens? What happens to them when the limelight dims? This is something addressed by Mark's recent film and immersive installation 'Council House Movie Star', which presents a world in which the drag character has an existence beyond the stage. Gale Force, a has-been drag queen, inhabits a council house filled with b-boys from the estate; racks of fading costumes; and the chipped plaster iconography of a Catholic Church, which has undoubtedly rejected her for her sexual predilections.

There is bleak humour and an entrenched comic sadness in this work. Gale is situated as a queer 'other' in a decaying environment, which mirrors her own faded career. The audience immerse themselves within this socio-queer context whilst gawping at the kitsch junk shop of her life, and the dead-end manoeuvres she uses to escape the ineffective efforts of a terminally depressed social worker (played by Helen) to rescue her. Gale is a metonym for the performer whose world caves in when muscles weaken; and waistline expands; and the audience leaves. The council house (or performance space) is empty because no one wants to know anymore, perhaps because we don't want to be reminded that this is our fate too.

Dying Swans offers an alternative examination of similar principles. Here, the obese, costumed, drag body is as constructed as the perfect bodies in dance marketing, make-up and fashion shoots. The photographs are, however, framed as loving spoofs of famous and iconic images of famous and iconic ballet stars (and Helen has managed to succeed where Mark's dance tutors failed and made him into a beautiful prima ballerina). And for the seconds it takes for a camera shutter to click, Mark is in third position, en pointe, and loving every minute of it, because although it hurts, it ends before the wobble defeats him.

There is the cruel comedy of an obese body positioned as a lithe and supple one bringing immediate parallels between two body forms. But here we put two fingers up to the establishment norm of zero sized dancers: this is our rebellion underscored with a dynamic visibility. When we watch an ageing dancer, obese or otherwise, what do we see? Are we watching the given performance, or are we watching an embedded memory of the performer they once were? And how do we watch the ageing performer without seeking the myth of who they once were and what they could once do?

The dying swan symbolises the tragic death of youth, and with it, beauty. Poignancy lies in unconscious allusion to the inevitable decline of a dancer's ability and stamina. Swans and ballerinas never speak; voices would break the spell of the ethereal aura with which they glide effortlessly over the surface of their corporeality. Beneath the water, the swan's feet are paddling. Beneath her breath, she might also be swearing, because beneath the glamour of the performance, her feet are aching, arthritic and deformed. Beauty is ephemeral; grace is a set-up, a Photoshop trope. Feet, en pointe in a Photoshopped image, do not ache; do not smell, do not stumble. Ballerinas do not fart.

Mark Edward is a part-time Senior Lecturer in Performance at Edge Hill University and a freelance dance maker, writer and performance artist. He likes to eat cake, drink Pimms and route around vintage furniture and clothes shops.

contact edwardm@edgehill.ac.uk

Dr Helen Newall is Reader in Performing Arts at Edge Hill University. She is a writer, photographer and visual projection artist. She likes sewing tutus behind closed doors and has tendencies to inveigle mature men into dragging up. contact newallhe@edgehill.ac.uk

(1) www.inter-disciplinary.net/wp-content/uploads/2011/04/ edwardppaper.pdf

(2) Dr Sara Houston, 2013, Ageing and Society in the UK in Diane Amans (Editor), Age and Dancing, Routledge, p16. 